\title{
Interferometric measurement of ionization in a grassfire
}

\author{
Kgakgamatso Marvel Mphale $\cdot$ M. Heron • \\ R. Ketlhwaafetse $\cdot$ D. Letsholathebe $\cdot$ \\ R. Casey
}

Received: 26 May 2006/ Accepted: 14 January 2010/Published online: 3 February 2010

(C) Springer-Verlag 2010

\begin{abstract}
Grassfire plumes are weakly ionized gas. The ionization in the fire plume is due to thermal and chemiionization of incumbent species, which may include graphitic carbon, alkalis and thermally excited radicals, e.g., methyl. The presence of alkalis (e.g., potassium and sodium) in the fires makes thermal ionization a predominant electron producing mechanism in the combustion zone. Alkalis have low dissociation and ionization potentials and therefore require little energy to thermally decompose and give electrons. Assuming a Maxwellian velocity distribution of flame particles and electron-neutral collision frequency much higher than plasma frequency, the propagation of radio waves through a grassfire is predicted to have attenuation and phase shift. Radio wave propagation measurements were performed in a moderate intensity $\left(554 \mathrm{~kW} \mathrm{~m}^{-1}\right)$ controlled grassfire at $30-$ and $151-\mathrm{MHz}$ frequencies on a $44 \mathrm{~m}$ path using a radio wave interferometer. The maximum temperature measured in the controlled burn was $1071 \mathrm{~K}$ and the observed fire depth was $0.9 \mathrm{~m}$. The radio wave interferometer measured attenuation coefficients of 0.033 and $0.054 \mathrm{~dB} \mathrm{~m}^{-1}$ for $30-$ and $151-\mathrm{MHz}$, respectively. At collision frequency of $1.0 \times 10^{11} \mathrm{~s}^{-1}$, maximum electron density was determined to be $5.061 \times 10^{15} \mathrm{~m}^{-3}$.
\end{abstract}

\section{List of symbols \\ $c \quad$ Speed of light in vacuum $\left(\mathrm{m} \mathrm{s}^{-1}\right)$ \\ $d \quad$ Propagation path length (m)}

K. M. Mphale ( $\varangle) \cdot$ R. Ketlhwaafetse $\cdot$ D. Letsholathebe Physics Department, University of Botswana,

P/Bag 0022, Gaborone, Botswana

e-mail: Mphalekm@mopipi.ub.bw

M. Heron · R. Casey

Marine Geophysical Laboratory, James Cook University,

Townsville, QLD 4811, Australia
$D_{c} \quad$ Degree of curing $(\%)$

$e \quad$ Electron charge $\left(-1.6 \times 10^{19} \mathrm{C}\right)$

$f_{0} \quad$ Propagation frequency $\left(\mathrm{s}^{-1}\right)$

$F_{d} \quad$ Flame depth (m)

$m_{e} \quad$ Mass of electron $\left(9.1 \times 10^{-31} \mathrm{~kg}\right)$

$M_{\text {sad }}$ Mass of dried sample $(\mathrm{kg})$

$N \quad$ Electron density $\left(\mathrm{m}^{-3}\right)$

$r \quad$ Residual fuel load $\left(\mathrm{kg} \mathrm{m}^{-3}\right)$

RoS Rate of spread $\left(\mathrm{m} \mathrm{s}^{-1}\right)$

$R_{x} \quad$ Receiver

$t_{r} \quad$ Resident time (s)

$T_{x} \quad$ Transmitter

$H_{c} \quad$ Heat of combustion $(\mathrm{J} / \mathrm{kg})$

$I_{g} \quad$ Fire line intensity $\left(\mathrm{kW} \mathrm{m}^{-1}\right)$

$W \quad$ Fuel load $\left(\mathrm{kg} \mathrm{m}^{-3}\right)$

$U_{1.5} \quad$ Windspeed at $1.5 \mathrm{~m}$ above ground $\left(\mathrm{m} \mathrm{s}^{-1}\right)$

$U_{2} \quad$ Windspeed at $2 \mathrm{~m}$ above ground $\left(\mathrm{m} \mathrm{s}^{-1}\right)$

$U_{10} \quad$ Windspeed at $10 \mathrm{~m}$ above ground $\left(\mathrm{m} \mathrm{s}^{-1}\right)$

\section{Greek symbols}

$\alpha_{\mathrm{f}} \quad$ Flame attenuation coefficient $\left(\mathrm{Np} \mathrm{m}^{-1}\right)$

$\beta_{0}=2 \pi f_{0} / c \quad$ Phase constant in vacuum $\left(\operatorname{rad~} \mathrm{m}^{-1}\right)$

$\beta_{\mathrm{f}} \quad$ Flame phase coefficient $\left(\operatorname{rad~m}{ }^{-1}\right)$

$\varepsilon_{0} \quad$ Permittivity in free space $\left(\mathrm{H} \mathrm{m}^{-1}\right)$

$\tilde{\gamma}_{\text {eff }} \quad$ Propagation constant

$\Delta \phi \quad$ Phase change $\left(\operatorname{rad~m}^{-1}\right)$

$\varphi_{\text {eff }} \quad$ Effective collision $\left(\mathrm{rad} \mathrm{s}^{-1}\right)$

$\omega \quad$ Radial propagation frequency $\left(\operatorname{rad~s}^{-1}\right)$

$\omega_{p}=\left(n e^{2} / m_{e} \varepsilon_{0}\right)^{1 / 2} \quad$ Plasma frequency $\left(\operatorname{rad~s}^{-1}\right)$

\section{Introduction}

Wildfire management agencies in Australia are concerned about radio wave communication reliability in extreme fire 
conditions (Boan 2007; Griffiths and Booth 2001). Several cases of failure to maintain radio wave communication at high frequency (hf) to very high frequency (vhf) through and in close proximity of wildfires have been reported in Australia, e.g., during the Lara bushfire disaster of 1969 (Williams et al. 1970) and Dwellingup bushfire disaster of 1961 (Foster 1976). An explanation of how this could happen is still sought. Williams et al. (1970) and Hata and Shigeyuki (1983), who studied super high frequency (shf) propagation in mass wildfires, attributed radio wave signal loss in wildfires to refraction and ionization in the fires. The researchers acknowledged that very high intensity wildfires could significantly affect radio signal strength due to heat-generated weakly ionized plasma in the plume. The generated plasma may lead to communication malfunction or even blackout (see for example, Hofmann 1966).

A chemi-ionization reaction, which involves excited methyl $\left(\mathrm{CH}^{*}\right)$ radical and oxygen atom $(\mathrm{O})$ is a known source of electrons in unseeded hydrocarbon flames (Butler and Hayhurst 1998; Alkamade et al. 1982). The reaction occurs in the flame's primary combustion zone where temperatures are in excess of $1000^{\circ} \mathrm{C}$. However, in flames such as moderate intensity wildfires, the reaction could be hindered by the availability of $\mathrm{O}$ atoms as the parent molecule $\left(\mathrm{O}_{2}\right)$ has high dissociation energy. Other sources of free electrons in unseeded flames are coagulated forms of carbon; graphite and soot, which are produced in significant quantities in wildfires (see Preston and Schmidt 2006). The carbon forms produce electrons by thermionic emission as they have low work functions (Sodha et al. 1963). The work function values for graphite and soot have been determined to be 4.35 and $8.5 \mathrm{eV}$, respectively (Shuler et al. 1954). In hydrocarbon flames seeded with alkali metals, the latter species become dominant electron sources. This is due to the fact that the species have low ionization energies, e.g., potassium has first ionization energy of $4.35 \mathrm{eV}$ (Semenov and Sokolik 1970). Wildfires are essentially hydrocarbon flames seeded with alkalibased nutrients (Mphale and Heron 2007).

The vegetation contains alkali and alkaline earth metal (AAEM) species as part of inherent inorganic ash. The AAEMs are mainly salts of potassium, calcium and sodium, which exist in different physical forms, with the species of potassium being a larger fraction of the inorganic ash. AAEMs can exist; ionically or organically attached to oxygen-containing functional groups (i.e., - $\mathrm{C}-$ ) of the organic structure of plants, as discrete particles in voids of the organic matrix and in solution form such as in xylem vessels. During a wildfire, AAEMs are released from a thermally crumbling plant structure and convectively drawn into the combustion zone of the fire. As potassium species form a larger fraction of the omnipresent inorganic particulates in plants, they are also a large fraction of inorganic emissions during plant matter combustion (Knudsen et al. 2004). The wildfire combustion zone is characterized by sufficiently high temperatures to cause thermal dissociation and ionization of alkalis (Vodacek et al. 2002). From studies of nutrient cycling, up to $28 \%$ of inherent potassium in plants is volatilized at a combustion efficiency of $98 \%$ (Raison et al. 1985). Vodacek et al. (2002) also estimate that $10-20 \%$ of potassium in vegetation is ionized in wildfires. Alkalis are estimated to produce electron densities in the range $10^{14}$ to $10^{17} \mathrm{~m}^{3}$ in wildfires (Boan 2006; Mphale and Heron 2007).

Electromagnetic wave propagation in weakly ionized gas is controlled by the medium's constitutive parameters, which are a factor of electron density and collision frequency (Zivanovic et al. 1964). However, at radio wave frequencies, the interaction of signals with a weakly ionized gas is mainly dependent on its electron density (Guo and Wang 2005). The higher the electron density, the higher will be the radio wave signal absorption. The paper reports on line-of-sight (LOS) signal amplitude measurements carried out at $\mathrm{hf}(30 \mathrm{MHz})$ and $\operatorname{vhf}(151 \mathrm{MHz})$ in a moderate intensity grassfire plume. The frequency bands used in the experiment were chosen for their relevance to fire fighting communication systems in rural Australia. In the experiment, signal phase change is also measured to further characterize the effect of fire on radio wave signals. Wildfire ionization was then determined from the measured parameters. Electron density measurements in wildfires are essential for fire-radio wave interaction model validation and numerical propagation prediction studies in similar environments.

\section{Ionization in wildfire}

There are two mechanisms that are responsible for wildfire plume ionization; these are thermal and chemical ionization processes (see Latham 1999). In thermal ionization, plume particles are selectively ionized based on both the temperature and ionization potential. Species with low ionization potential in a high temperature environment are easily ionized. Ionization by the processes could be determined using the Saha equation (Haught 1962). In the combustion zone, the AAEMs are dissociated into atoms. The hot environment excites the atoms, which lose their outer shell electrons according to the following equation (Nesterko and Taran 1971):

$\mathrm{AM}^{*} \leftrightarrow \mathrm{AM}^{+}+\mathrm{e}^{-}$

where $\mathrm{AM}^{*}, \mathrm{AM}^{+}$and $\mathrm{e}^{-}$are excited alkali metal, the metal ion and electron, respectively.

A large number of different ions exist in fire plumes. Some of these ions are involved in energetic chemical 
ionization reactions. It is known that excited methyl $\left(\mathrm{CH}^{*}\right)$ radicals, chlorine ions $\left(\mathrm{Cl}^{-}\right)$, hydrogen atoms $(\mathrm{H})$ and acetylene $\left(\mathrm{C}_{2} \mathrm{H}_{2}\right)$ molecules react with each other to give electrons in flames (Semenov and Sokolik 1970). The methyl radical reacts with acetylene to give electrons, according to the following equation (Alkamade et al. 1982):

$\mathrm{CH}^{*}+\mathrm{C}_{2} \mathrm{H}_{2} \leftrightarrow \mathrm{C}_{3} \mathrm{H}_{3}^{+}+\mathrm{e}^{-}$.

Chlorine ions, which exist in substantial amounts in vegetation fires (Mphale 2008), react with hydrogen radical to produce hydrogen chloride gas and electrons according to the equation:

$\mathrm{H}+\mathrm{Cl}^{-} \leftrightarrow \mathrm{HCl}+\mathrm{e}^{-}$.

However, the production of electrons by Eq. (3) could be hampered by the presence of alkalis, which compete for $\mathrm{Cl}^{-}$with the $\mathrm{H}$ radical. Alkalis react with chlorine to produce metal chlorides.

\section{Radio wave interferometry}

\subsection{Theory}

An interferometer can be arranged to measure both signal attenuation and phase shift at a suitable frequency determined by collision frequency and electron density of a medium under diagnosis (Caron et al. 1968; Howlader et al. 2005). It has advantages over other conventional methods, e.g., use of Langmuir probes, of being nonintrusive and provides a direct measurement of attenuation. The use of Langmuir probes is limited to measuring local electron density and carries with it some inherent problems such as probe heating and local plasma perturbation. At microwave frequencies, an interferometer has been used to measure line-integrated plasma electron density and collision frequency of laboratory-scale weakly ionized plasma (Zivanovic et al. 1964; Gilchrist et al. 1997). Apart from being expensive, microwave interferometers are fragile equipment and may not be suitable for outdoor deployment. Diagnosis of large unbound tenuous atmospheric pressure ionized plumes, such as wildfires, may require outdoor deployment of an interferometer. A robust and relatively cheap radio wave interferometer could be appropriate for the task.

At atmospheric pressure, weakly ionized gases, such as flames, are highly collisional with frequencies of about a tenth of a terahertz $\left(10^{11} \mathrm{~Hz}\right)$ (e.g., in Jamison et al. 2003). When the probe signal of an interferometer is HF or VHF, radio waves $\left(\varphi_{\text {eff }} / \omega\right)>1$ and $\left(\omega_{\mathrm{p}} / \omega\right)>1$. In this case, propagation theory, e.g., in Hofmann 1966, predicts transmission through a wildfire with significant attenuation.
Consider a plane polarized radio wave to traverse a weakly ionized flame medium of average propagation path length $d$ in the positive $x$-direction, then its amplitude $\left(E_{f}\right)$ is given by the relation (Santoru and Gregorie 1993):

$E_{f}(x)=E_{0} \exp \left\{-\int_{0}^{d} \tilde{\gamma}_{\text {eff }}(x) \mathrm{d} x\right\}$

where $E_{0}$ is free space electric field strength of the electromagnetic signal. The effective propagation constant $\left(\tilde{\gamma}_{\text {eff }}\right)$ is complex and is related to attenuation $\left(\alpha_{\mathrm{f}}\right)$ and shift $\left(\beta_{\mathrm{f}}\right)$ coefficients in the flame medium by the expression (Laroussi and Roth 1993):

$\tilde{\gamma}_{\text {eff }}=\alpha_{\mathrm{f}}+i \beta_{\mathrm{f}}$.

Based on high collisionality and weak ionization in fire medium, Mphale and Heron (2007) approximated radio wave propagation coefficients $\alpha_{\mathrm{f}}$ and $\beta_{\mathrm{f}}$ in (5) as:

$\alpha_{\mathrm{f}} \cong \frac{\omega}{\mathrm{c}}\left[\frac{\omega_{\mathrm{p}}^{2}}{2 \omega \varphi_{\mathrm{eff}}}\right]$

and

$\beta_{\mathrm{f}} \cong \frac{\omega}{\mathrm{c}}\left[1+\frac{\omega_{\mathrm{p}}^{4}}{8 \varphi_{\mathrm{eff}}^{2}} \frac{1}{\omega^{2}}\right]$

The attenuation and phase coefficients in (6) and (7) provide useful information about the electromagnetic properties (electron density and collision frequency) of the medium, e.g., in Akhtar et al. 2003 and Koretzsky and Kuo (1998).

Considering the real part of Eq. (4), radio wave signal attenuation is determined from signal intensity in free space relative to that in fire medium and is given by the following expression (Schneider and Hofmann 1959):

$$
\begin{aligned}
& \operatorname{Attn}(\mathrm{dB})=10 \log _{10}\left\{\left(\frac{E_{0}}{E_{f}}\right)^{2}\right\} \\
& \operatorname{Attn}(\mathrm{dB})=20 \log _{10}\left\{e^{\alpha_{\mathrm{f}}}\right\}
\end{aligned}
$$

Induced phase change is related to phase coefficient in free space and that in fire medium and is given by the expression (Howlader et al. 2005):

$$
\begin{aligned}
& \Delta \phi=\int_{0}^{d}\left(\beta_{\mathrm{f}}-\beta_{0}\right) \mathrm{d} x \\
& \Delta \phi=\frac{\omega}{c} \int_{0}^{d}\left\{\left[1+\frac{\omega_{p}^{4}}{8 \varphi_{\mathrm{eff}}^{2}} \frac{1}{\omega^{2}}\right]-1\right\} \mathrm{d} x
\end{aligned}
$$

From Eqs. (8) and (9), a grassfire flame with an average electron density $(n)$ induces phase change $(\Delta \phi)$ and attenuation on radio waves given by the relations (10) and (11), respectively: 
$\Delta \phi=\left\{\beta_{\mathrm{f}}-\beta_{0}\right\} d=\frac{e^{2}}{16 c \pi m_{\mathrm{e}}^{2} \varepsilon_{0}^{2}} \frac{n^{2} d}{f_{0} \varphi_{\mathrm{eff}}^{2}}$

$\Delta \phi=0.00067 \frac{n^{2} d}{f_{0} \varphi_{\mathrm{eff}}^{2}}$

and attenuation $=\alpha_{\mathrm{f}} d$; therefore

$\alpha_{\mathrm{f}} d=\frac{e^{2}}{2 c m_{\mathrm{e}} \varepsilon_{0}} \frac{n d}{\varphi_{\mathrm{eff}}}=5.292 \times 10^{-6} \frac{n d}{\varphi_{\mathrm{eff}}}$

Dividing Eq. (10) by (11) gives electron density as:

$n=0.0079 f_{0} \varphi_{\text {eff }} \times \frac{\Delta \phi}{\mathrm{Attn}}$

Uhm (1999) relates flame gas collision frequency to its temperature by the relation

$\varphi_{\mathrm{eff}}=1.36 \times 10^{12} \frac{T_{r}}{T_{g}}\left(T_{e}\right)^{1 / 2}$

where $T_{r}, T_{g}$ and $T_{e}$ are ambient, flame and electron temperatures, respectively. Sicha (1979) observed that electron temperature in flame at about $1000 \mathrm{~K}$ is $0.1 \mathrm{eV}$.

\subsection{Radio wave interferometer}

Radio wave interferometer is an instrument designed to use the same principles as the microwave interferometer except that it works at a much lower frequency and is suitable for measuring ionization of large unbounded volumes of slightly ionized gases at atmospheric pressure such as wildfires.

The interferometer has six units whose primary functions are to synthesize, transmit, receive and process phase coherent radio signals. The units perform the above functions on 6-, 30- and 150-MHz signals. The block diagram in Fig. 1 shows all the units making up the radio wave interferometer. The specific functions of the units are discussed in Sect. 4.4.

\section{Experimental methods}

\subsection{Prescribed grassfire}

\subsubsection{Study site and vegetation structure}

The study site was located at $147^{\circ} 58^{\prime} 56^{\prime \prime} \mathrm{E}$ and $19^{\circ} 25^{\prime} 46^{\prime \prime} \mathrm{S}$ on the western side of James Cook University's main campus in Townsville, Queensland. The climate in the Townsville region is warm and humid (Lokkers 2000). Summers are hot with an average maximum temperature of $30.7^{\circ} \mathrm{C}$ in January. An average minimum temperature of $15.4^{\circ} \mathrm{C}$ occurs in winter (July). The region receives an average annual rainfall of $1143 \mathrm{~mm}$ (Williams et al. 2003). Most of it falls during summer; a season that extends from December to March. The rainfall in this season is generally associated with the northeasterly trade winds, cyclones and

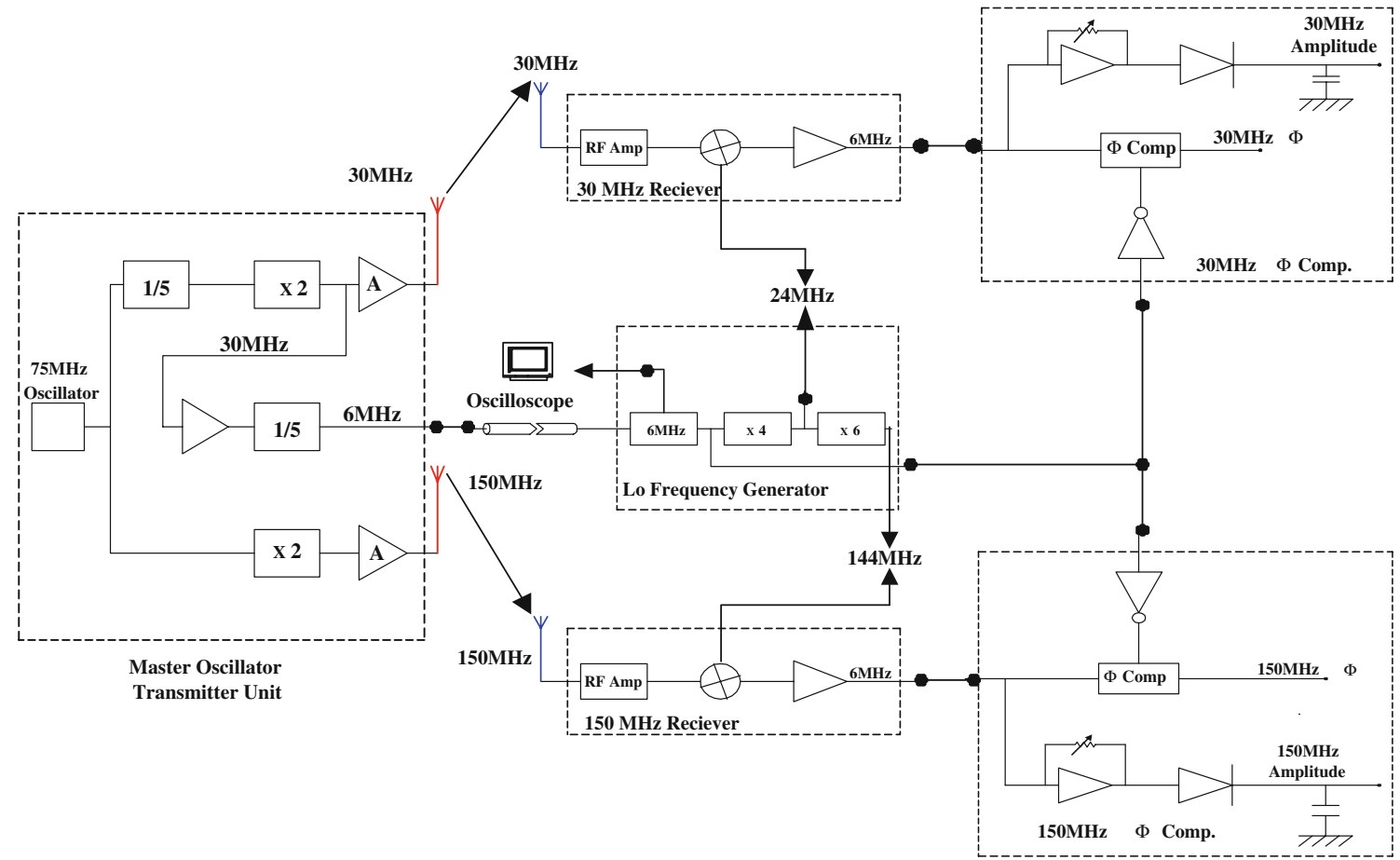

Fig. 1 A block diagram for a radio wave interferometer 
depressions (Lokkers 2000). Long dry periods during the winter and variable annual rainfall have resulted in the region being fire-prone, and frequent fires have created mosaics of open forest, woodlands and grasslands in the region.

The vegetation structure in the study site consists of open woodlands of eucalyptus and grassy understorey. The understorey is mainly black spear grass and there are occasional 1.5-3 m high chinee-apple shrubs. The average spear grass density and height were $150 \mathrm{plants} / \mathrm{m}^{2}$ and $1.0 \mathrm{~m}$, respectively. The dominant overstorey tree species were poplar gums eucalyptus (see Fig. 2).

The site was irregular in shape (see Fig. 9) with a perimeter of $393 \mathrm{~m}$. A propagation path of about $44 \mathrm{~m}$ long was chosen at the site in an area where there was minimum obstruction from trees and shrubs. The site was chosen along with others by the Physical Planning Division of the University for Controlled burning in 2004, a preemptive exercise necessary for the control of high intensity wildfires occurrence on the campus. The amount of fuel accumulated and the proximity to building structures were the main reasons for the selection of these plots.

\subsubsection{Fuel characteristics}

Vegetation was sampled by means of $1 \mathrm{~m}^{2}$ quadrants. Four $1 \mathrm{~m}^{2}$ quadrants were randomly set up $1 \mathrm{~h}$ before ignition in the prescribed burn area. Twenty (20) spear grass plants were randomly sampled in each quadrant. The height of each plant was measured by a $5-\mathrm{m}$ measuring tape and then averaged to give the average fuel height $\left(H_{a}\right)$. Surface litter and vegetation (clipped from just above the ground surface) were collected from the quadrants into separate bags (a bag for each quadrant) and then sealed for analysis. The mass of plant material from each quadrant was determined and the masses were then averaged to give $W$. Weighed

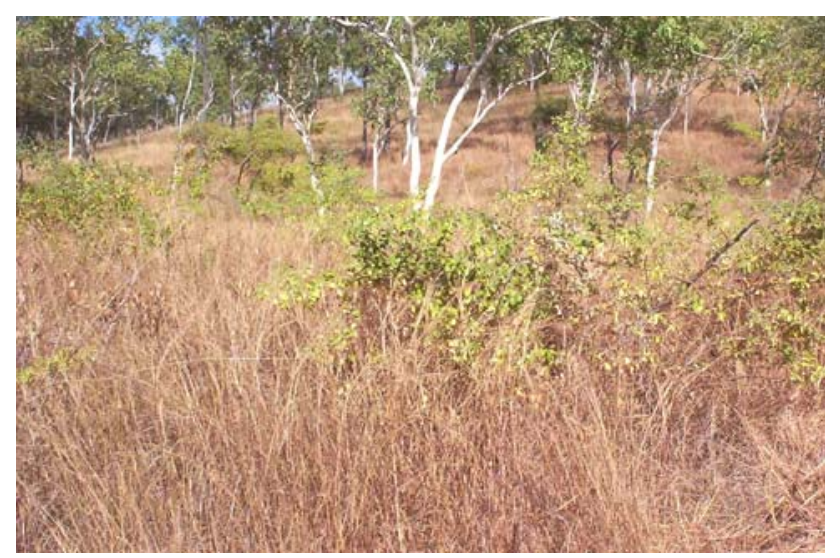

Fig. 2 Vegetation structure at the study area samples of plant material from each bag were then dried in an oven set at $60^{\circ} \mathrm{C}$ for $72 \mathrm{~h}$. The oven-dried plant materials were thereafter re-weighed to give dry mass, which averaged to give $M_{\mathrm{sad}}$. The degree of curing $\left(D_{c}\right)$ for the fuel was determined from the relation:

$D_{c}=\left(1-\left(\frac{W-M_{\mathrm{sad}}}{W}\right)\right) \times 100 \%$

Fuel load $\left(F_{L}\right)$ for the study area was calculated from the averaged biomass per unit area; thus

$\mathrm{F}_{L}\left(\mathrm{~kg} / \mathrm{m}^{2}\right)=W$.

\subsection{Measurement of grassfire behavior}

The magnitude of radio wave signal attenuation is dependent on fire behavior (i.e., intensity and fire depth), e.g., in Boan (2007). Therefore, it is important that the grassfire behavior is fully characterized in the experiment for the attributes to be related to the measured attenuations. In the controlled burn, fire was ignited such that its front was in the direction of the prevailing wind. During the experiment, wind blew from the northeast direction $\left(60^{\circ} \mathrm{E}\right)$ (see Fig. 3). The propagation equipment was set such that radio waves propagate approximately in the west to east direction. The rate of spread (RoS) for the grassfire was determined from running the CSIRO Fire Spread Calculator v.1 (CSIRO 1998). Fire Spread Calculator is a Windows ${ }^{\circledR}$ based program that calculates RoS for different vegetation scenarios in Australia including northern Australia's open woodland vegetation. The inputs to this model are ambient temperature, relative humidity, curing percentage and wind speed $(\mathrm{km} / \mathrm{h})$ at $10 \mathrm{~m}$. From the RoS determined from the Fire Spread Calculator, the flame depth of the grassfire was

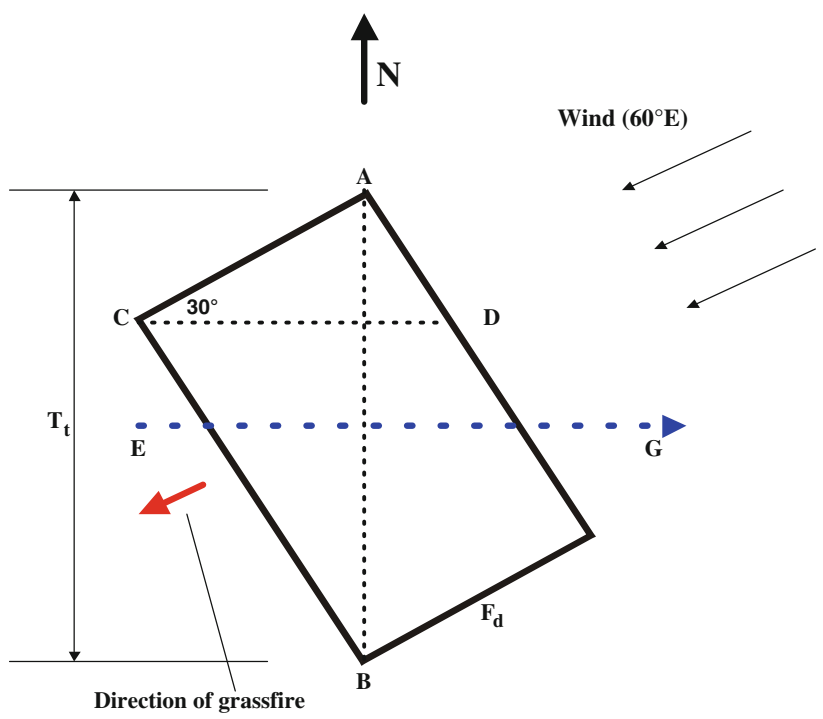

Fig. 3 Observed grassfire direction during the prescribed burn 
calculated by considering that the flame front intercepted the transmission path at an angle of $30^{\circ}$ (Fig. 3).

Noting that the grassfire was frontal or line fire, its flame depth $\left(F_{d}\right)$ was proportional to flame residence time $\left(t_{r}\right)$ or the time the flame took to cross the propagation path. The constant of proportionality is the RoS; thus

$F_{d}=\operatorname{RoS} \times t_{r}$

Residence time $\left(t_{r}\right)$ for the flame is to be determined from radio wave propagation measurements. By inspection angle DAB in Fig. 3 is $30^{\circ}$. Also from the figure, $F_{d}$ can be calculated as follows:

$$
\begin{aligned}
& F_{d}=\mathrm{AB} \times \sin \left(30^{\circ}\right) \\
& F_{d}=(1 / 2) \times \mathrm{AB}
\end{aligned}
$$

From Eqs. (16) and (17), the rate of spread (RoS) is given by

$\operatorname{RoS}=\frac{\mathrm{AB}}{2 t_{r}}$

The intensity of the grassfire is calculated from Byram's fire line intensity relation given by Sullivan (1997) as:

$I_{\mathrm{gf}}=H \times(W-r) \times \operatorname{RoS}$

where $r$ is residual weight. It was observed that during the controlled burn, all of the surface fuel burnt; thus, $r \approx 0$ in (19).

\subsection{Temperature measurements}

Grassfire caused signal attenuation occurs when the fire crosses the propagation path. The interception can be detected by putting thermal sensors (thermocouples) in the propagation path ahead of the fire front. A signal attenuation, which occurs at the same time with the measured temperature maxima, could then be assumed to be caused by fire and hence the need for temperature measurements in the experiment.

A thermocouple tree of about $1.25-\mathrm{m}$ high was constructed from a steel pipe of diameter $0.025 \mathrm{~m}$ (see Fig. 4). Steel rods (arms) of length $0.4 \mathrm{~m}$ were attached at every $0.25 \mathrm{~m}$ of the tree's height to hold up to five thermocouples. Thermocouples were cut from a 100-m double braided fiberglass-insulated chromel-alumel (24-G/G) thermocouple wire, $50 \mu \mathrm{m}$ in diameter. The thermocouple wire has a fiberglass shield, which can withstand temperatures up to $450^{\circ} \mathrm{C}$. At temperatures greater than $450^{\circ} \mathrm{C}$, the fiberglass shield fuses. Our tests showed that the insulation properties hold for higher temperatures, but the material then becomes brittle on cooling, and therefore can be used only once.

The type $K$ thermocouple wires were electro-fused at one end to make perfect junctions and tested with a hot

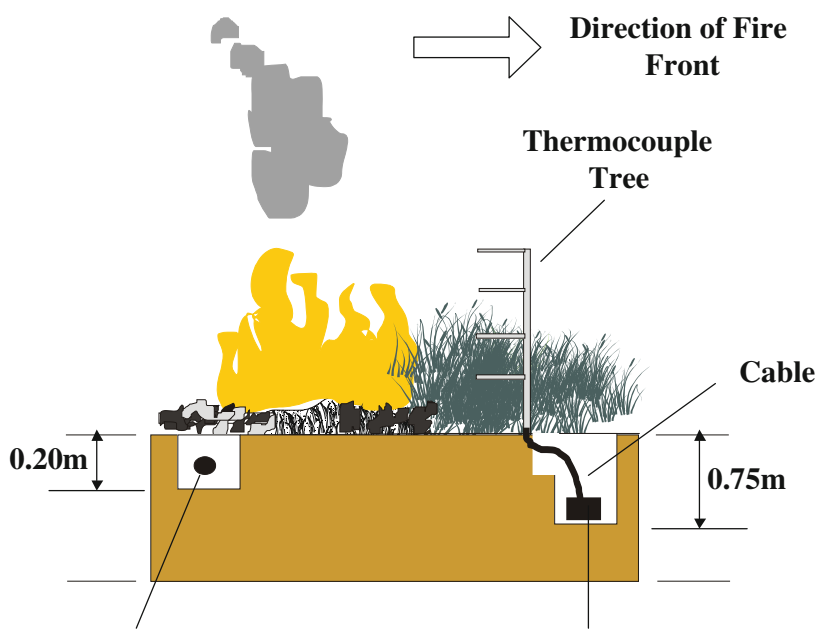

Cable for Phase

Measurement

Spectrum 1700 logger

Fig. 4 Thermocouple tower set up (not drawn to scale)

air gun and a multimeter. The thermocouples were then fixed to tree arms by means of muffler tape, and the electro-fused junctions were left protruding $0.01 \mathrm{~m}$ beyond the arm length into the flame. The thermocouple wires were buried in a shallow trench $(0.1 \mathrm{~m}$ deep) and connected to the thermocouple logger $3 \mathrm{~m}$ away from the thermocouple tree at a spot that allowed access without trampling the fuel in the immediate vicinity of the thermocouples.

The thermocouples were wired to a SPECTRUM ${ }^{\circledR}$ SP $1700-51 \mathrm{~W}$ thermocouple data logger to read in temperatures into the data logger's internal memory throughout the experiment. Operational cold junction temperature of the data logger ranges from -45 to $85^{\circ} \mathrm{C}$; therefore, it was necessary to protect the logger from heating beyond $85^{\circ} \mathrm{C}$, as this may invalidate the data. The data logger was dug $0.75 \mathrm{~m}$ into the ground and wrapped around with an insulating material (Fiberflex ${ }^{\circledR}$ ) to protect it from heat that may the produced in the grassfire. SP $1700-51 \mathrm{~W} \log$ ger has the capability to read temperatures up to $1370^{\circ} \mathrm{C}$ and is therefore ideal for measuring bushfire flame temperatures.

\subsection{Interferometer units}

\subsubsection{Master oscillator and transmitter unit}

The unit is responsible for generating phase coherent 6-, $30-$ and $150-\mathrm{MHz}$ radio wave signals from a $75-\mathrm{MHz}$ master oscillator. A $75-\mathrm{MHz}$ square wave signal is frequency divided by 5 using logic circuits; it is then doubled $(\times 2)$ to produce a $30-\mathrm{MHz}$ sinusoidal signal. The $30-\mathrm{MHz}$ signal is then amplified to a power rating of $250 \mathrm{~mW}$ and fed to a $30-\mathrm{MHz}$ antenna. A part of the $30-\mathrm{MHz}$ signal is 
tapped, buffered and then divided by 5 to produce a $6-\mathrm{MHz}$ reference signal. This reference signal is fed at low impedance to a 75-m long coaxial cable and connected to the receiver unit $\left(R_{x}\right)$. The $75 \mathrm{MHz}$ was doubled to produce a $150-\mathrm{MHz}$ sinusoidal signal. It was then amplified and fed to a $150-\mathrm{MHz}$ Yagi antenna. The unit produced phasecoherent signals, since they were produced from one oscillator: the $75-\mathrm{MHz}$ master oscillator.

\subsubsection{Local oscillator generator (LOG) and receiver $\left(R_{x}\right)$ units}

The main function of these units is to receive the transmitted signals from the master oscillator-transmitter unit and synthesize a 6-MHz signal for phase comparison. Generally, LOG generates signals for mixing in the $R_{x}$ units. The LOG unit is fed with the 6-MHz reference signal from the master oscillator and transmitter unit. The reference signal is frequency-multiplied by 4 and 6 , respectively, to produce $24-$ and $144-\mathrm{MHz}$ signals (Fig. 4). In the $30-\mathrm{MHz} R_{x}$ unit, a received signal from the $30-\mathrm{MHz}$ antenna is mixed with a $24-\mathrm{MHz}$ signal from the local oscillator frequency generator to produce $6 \mathrm{MHz}$. The 150$\mathrm{MHz}$ signal received from a Yagi antenna is mixed with a 144-MHz signal from the LOG to produce $6 \mathrm{MHz}$. The 6$\mathrm{MHz}$ signals and the reference $6 \mathrm{MHz}$ are fed in respective phase comparators.

\subsubsection{Comparators}

These are $180^{\circ}$ phase comparison circuits. The phase of 6$\mathrm{MHz}$ signals from $R_{x}$ units is compared with the phase of the 6-MHz reference. A DC voltage representative of this phase difference is registered in a $\mathrm{HOBO}^{\circledR}$ data logger. Initially, a voltage of $2.5 \mathrm{~V}$ was set for the $180^{\circ}$ phase difference.

\subsubsection{Antennae}

Two types of antennae were used in the interferometer; a horizontal Yagi (Fig. 5) and vertical quarter-wavelength whip (Fig. 6). The Yagi antenna was designed to work at a frequency range of $149-151 \mathrm{MHz}$, and the vertical quarterwavelength whip at $30 \mathrm{MHz}$.

The Yagi antenna had a highly directional type of radiation pattern. At near field, a nominal gain of the antenna was $11.4 \mathrm{dBd}$. From its radiation pattern in the Eplane, $3 \mathrm{~dB}$ was at $34^{\circ}$, while the pattern in the $\mathrm{H}$-plane, $3 \mathrm{~dB}$ was at $43^{\circ}$. Radiation pattern for the $30-\mathrm{MHz}$ quarter wavelength whip antenna was omnidirectional.

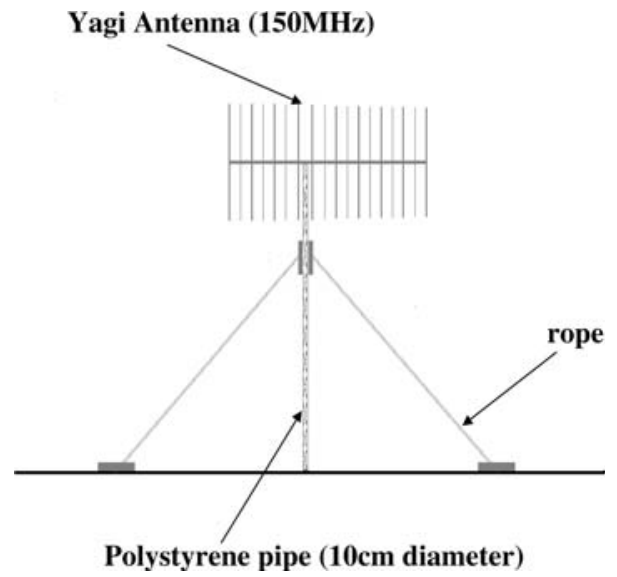

Fig. 5 A 150-MHz Yagi antenna

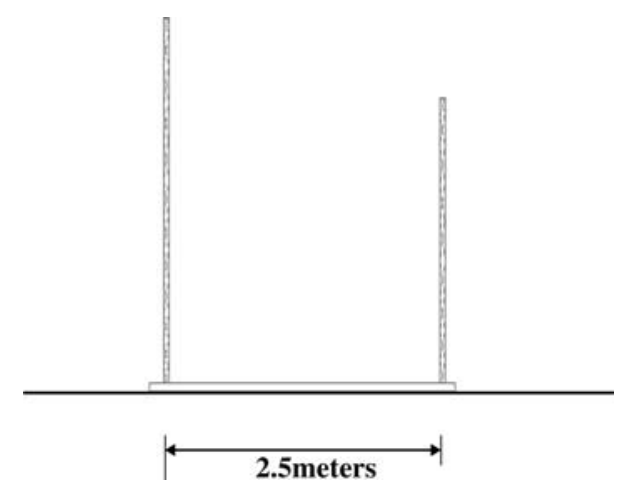

Fig. 6 Quarter-wavelength whip antenna

\subsubsection{Phase change tests and calibration of comparator unit}

The interferometer was tested for sensitivity to phase changes using antenna position shifts. In the tests, an oscilloscope was used to monitor the output from the 30$\mathrm{MHz}$ phase comparator unit. The quarter wave dipole was initially set at position A (PsA) so that the amplitude signal and the reference signal (shown as a square wave in Fig. 7a) were in phase. The antenna was moved a fraction of the wavelength away from PsA. When the antenna was moved $2.9 \mathrm{~m}(0.29 \lambda)$ away from PsA, a phase shift of $55^{\circ}$ was induced (calculated from Fig. 7b). Theoretically, a phase shift of $54^{\circ}$ should be imposed on the radio wave; therefore, the comparator circuit responded very well to the change in the antenna position.

When the antenna was moved $5.0 \mathrm{~m}(0.5 \lambda)$ away from PsA, a phase shift of $90^{\circ}$ was induced on the amplitude signal (as calculated from Fig. 8b). 
Fig. 7 Phase change due to moving the antenna: a phase at the starting position (PsA) and b antenna moved $2.9 \mathrm{~m}$ away from the starting position (a)

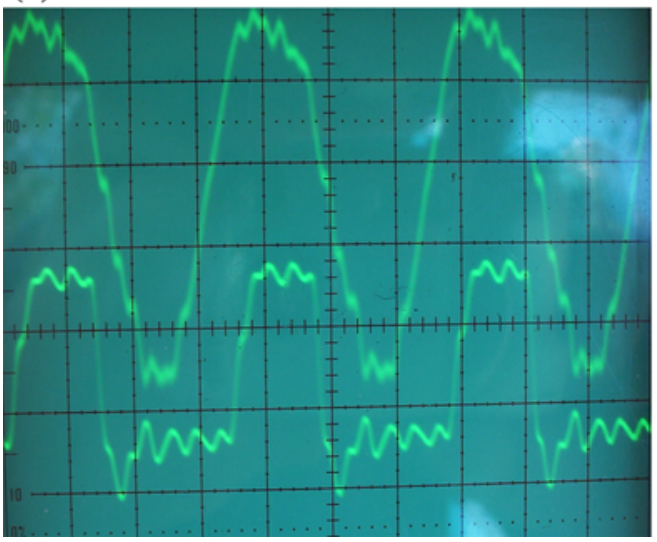

(b)

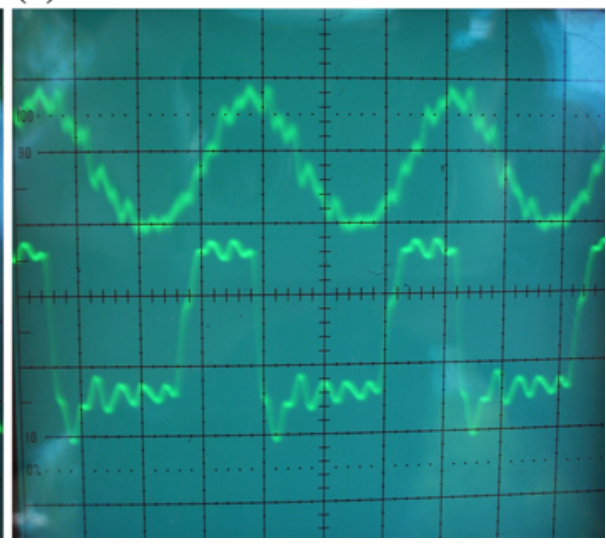

(a)

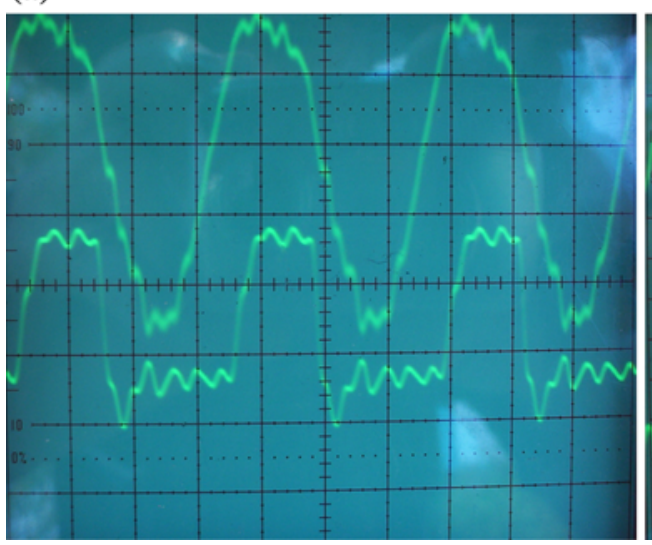

(b)

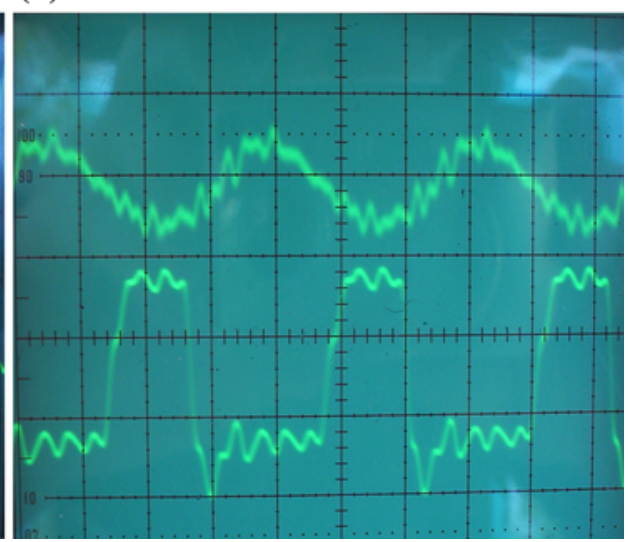
moving the antenna: a phase at the starting position (PsA) and b antenna moved $5.0 \mathrm{~m}$ away from the starting position

\subsection{Radio wave propagation measurements}

\subsubsection{Propagation and phase measurement path}

The transmitters and receivers were set up on opposite sides of the plot, separated by a direct distance CA-CD (Figs. 9, 10 ) of $44 \mathrm{~m}$. A $75-\mathrm{m}$ long $75 \Omega$ coaxial cable used for phase change measurement was dug $0.20 \mathrm{~m}$ in the ground. The purpose of the trench was to protect the cable from the heat that may diffuse into the ground. At this depth, the heat from the grassfire is negligibly small that it cannot influence the phase measurements. During the propagation measurement, the cable ran far from where the head fire intercepted the transmission path. The cable was set such that $\mathrm{CD}-\mathrm{CC}$ was $10.3 \mathrm{~m}, \mathrm{CC}-\mathrm{CB}$ was $25.5 \mathrm{~m}$ and CB-CA was $9.5 \mathrm{~m}$ to connect to both $30-\mathrm{MHz}$ receiver and transmitter units.

The transmitter, receiver and the rest of the units were enclosed in polysterene boxes to prevent heat from the fire affecting the circuitry. A polystyrene board was placed over the boxes to act as shade for both the boxes and the cables that connect to the antennas. The boards were placed over the boxes in such a way that it allowed circulation around the enclosures. A thermocouple was connected to a $\mathrm{HOBO}^{\circledR}$ data logger and placed inside the boxes to monitor the temperature inside the boxes.

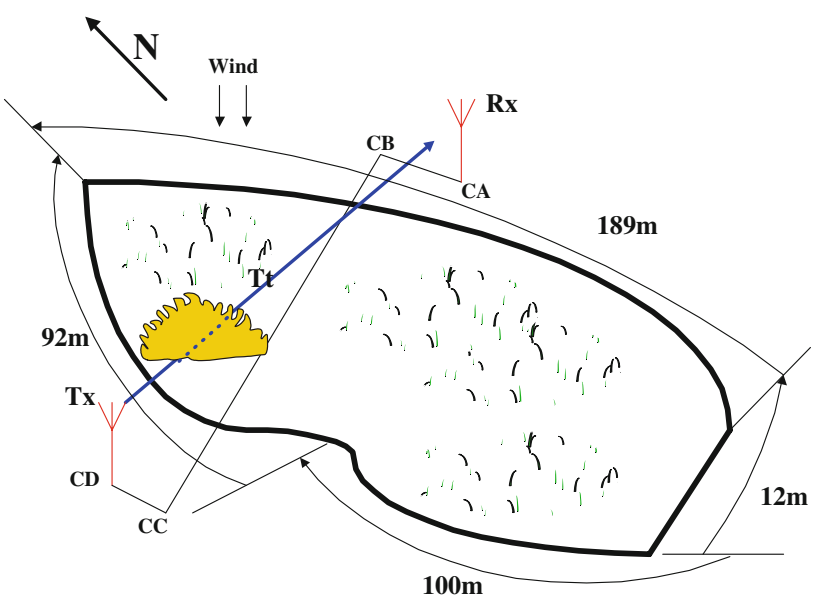

Fig. 9 Propagation paths and the shape of the study area plot (not drawn to scale)

\subsubsection{Signal amplitude measurement}

The 150- and $30-\mathrm{MHz}$ modules were tested for stability days before the controlled burn. It was noted that the 150 $\mathrm{MHz}$ module was not stable; only the $30-\mathrm{MHz}$ module passed the test. The $150-\mathrm{MHz}$ module was replaced by a 
Fig. 10 Effects of scattering on 151-MHz (a) and 30-MHz (b) amplitude signals

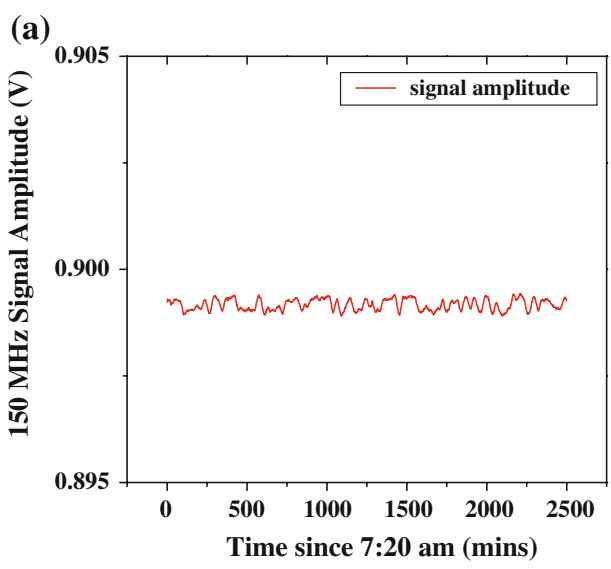

commercial 151-MHz module and we had to cancel the phase measurements at this frequency.

The 30- and 151-MHz modules were set (on different days) and left to run for a period of 2572 and $1209 \mathrm{~min}$, respectively. It was observed that the $30-\mathrm{MHz}$ signal fluctuated around an average amplitude of $2011.06 \mathrm{mV}$ with the maximum and minimum amplitudes of 2011.32 and $2010.80 \mathrm{mV}$, respectively. Standard deviation from the mean amplitude was calculated to $0.10 \mathrm{mV}( \pm 0.001 \mathrm{~dB})$. The $151 \mathrm{MHz}$ fluctuated from average amplitude of $899.17 \mathrm{mV}$ with maximum and minimum amplitudes of 899.44 and $898.90 \mathrm{mV}$, respectively. The standard deviation of the signal from its mean amplitude was $0.13 \mathrm{mV}( \pm 0.003 \mathrm{~dB})$. It is interesting to note that the signal fluctuations were random and occurred both during the night and day and therefore cannot be alluded to variations in humidity and temperature during the cycle. Besides, the propagation distance $(41 \mathrm{~m})$ was too short to consider significant refractive effects on the signals.

\section{Experimental results and discussions}

\subsection{Grassfire temperature}

There is a discrepancy between the actual combustion gas temperature and that measured by a bare bead thermocouple (Dupuy et al. 2003; Brohez et al. 2004). The error is mainly due to the convection and radiation heat transfer to and from thermocouple bead. The error, which could be up to $200 \mathrm{~K}$, is also attributable to bead physical characteristics such as emissivity and size (Shannon and Butler 2003). However, the actual flame gas temperatures could be reconstructed from thermocouple readings using heat balance equation. The discrepancy between the actual combustion gas and thermocouple measured temperature is given by Silvani and Morandini 2009 as

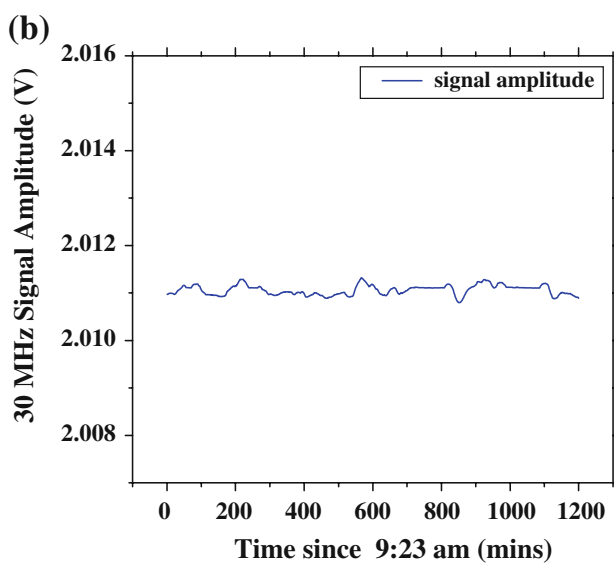

$T_{\mathrm{cg}}-T_{\mathrm{tc}}=\frac{\sigma \varepsilon_{\mathrm{tc}}\left(1-\varepsilon_{\mathrm{cg}}\right) T_{\mathrm{cg}}^{4}}{h_{\mathrm{tc}}+4 \sigma \varepsilon_{\mathrm{tc}} T_{\mathrm{cg}}^{3}}$

where $h_{\mathrm{c}}=k N u / d_{\mathrm{tb}}$ is the heat transfer coefficient. $N u, k$ and $d_{\mathrm{tb}}$ are Nusselt number, diffusivity and bead diameter, respectively. Diffusivity is related to the specific heat capacity $\left(C_{p}\right)$ and Prandtl number $(P r)$ by the relation, $k=\mu C_{p} / P r$. For combustion gases, $\operatorname{Pr}$ is 0.71 . Following Dupuy et al., Eq. (20) is solved for $T_{\text {cg }}$, which is actual flame gas temperature, and this correction was applied on the thermocouple measured temperature. With this correction, it was observed that the discrepancy is more than $40 \mathrm{~K}$ for temperatures above $500 \mathrm{~K}$.

The maximum corrected thermocouple temperature measured in the grassfire was $1071 \mathrm{~K}$. This occurred at $0.75 \mathrm{~m}$ above the ground surface at 10.44:50 a.m. It coincided with maximum temperatures at heights 0.25 and $0.50 \mathrm{~m}$ above the ground, which were 689 and $862 \mathrm{~K}$, respectively. At $1.00 \mathrm{~m}$, the maximum temperature occurred between 10.44:40 and 10.44:50 a.m. and was $786 \mathrm{~K}$. This was because the flame was wind-blown toward the thermocouple tree, therefore reaching the thermocouple at $1 \mathrm{~m}$ earlier than others at lower heights. Considering that flaming combustion occurs at temperatures above $500 \mathrm{~K}$, e.g., in Cruz (2008), therefore from Fig. 11 and data from the SPECTRUM ${ }^{\circledR}$ logger, it can be deduced that the flame residence $\left(t_{r}\right)$ time was on average $32 \mathrm{~s}$. This could also be observed from attenuation measurements.

\subsection{Attenuation of 151-MHz signal}

From the amplitude signal graph (Fig. 12), there was a lot of commotion up to 2 min before the grassfire crossed the propagation path. The signal fluctuations between $\mathbf{A}$ and $\mathbf{B}$ were identified as those due to the university fire suppression crew moving up and down a fire break next to receiver units. Fluctuations between $\mathbf{B}$ and $\mathbf{C}$ were identified as due to a crew member intercepting the propagation 
Fire temperature at various heights above ground level.

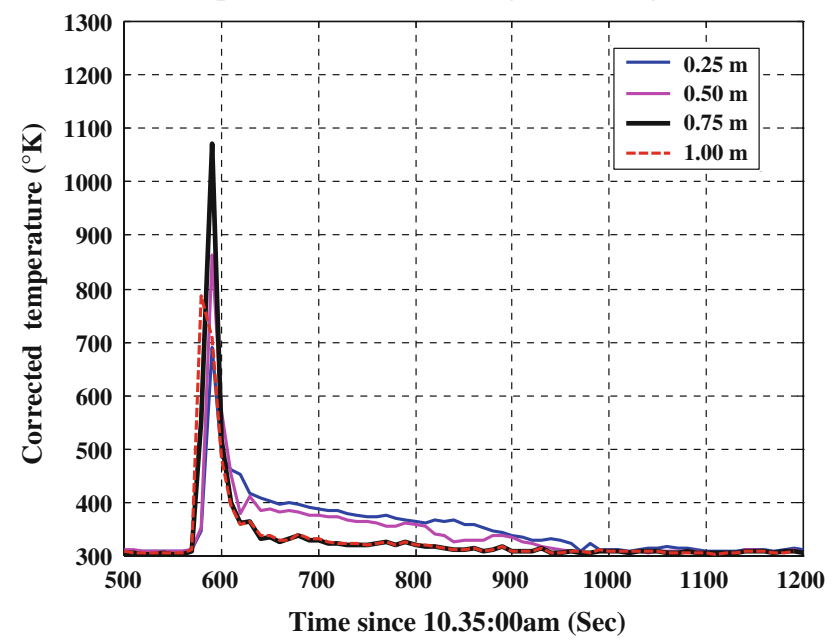

Fig. 11 Grassfire flame temperatures as they intercepted the propagation path

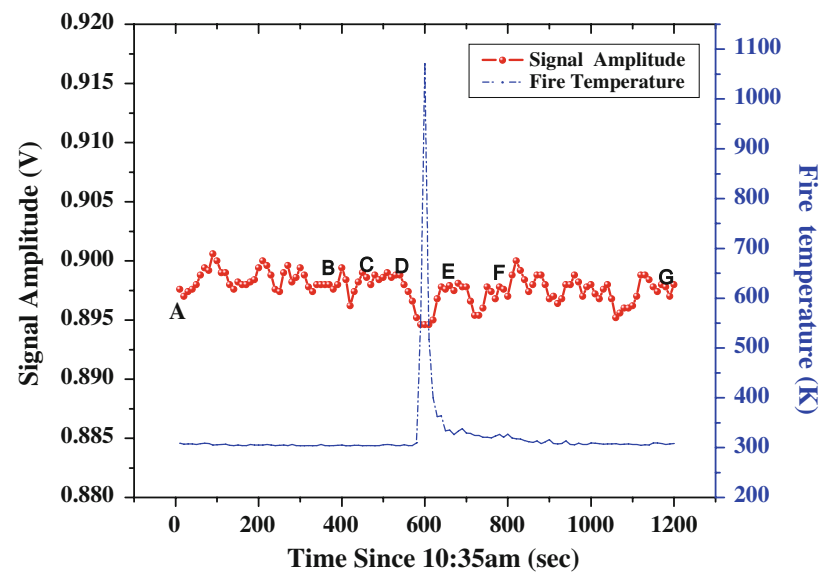

Fig. 12 151-MHz Signal amplitude versus time

path at 10.42 a.m. A prominent drop in the signal amplitude D-E was observed when the grassfire flame crossed the propagation path. A minute or two after the fire crossed the propagation path, the fire crew moved into extinguish it before it got out of control. This was observed in the drops that occurred in the region $\mathrm{E}$ to $\mathrm{G}$ of the signal amplitude graph.

The time between 10.42:30 and 10.46:30 a.m. was considered for attenuation calculation as it coincided with temperature maxima measured form the thermocouple tree (Fig. 12). Based on the amplitudes between points $\mathrm{D}$ and $\mathrm{E}$, attenuation (dB) was calculated using Eq. (8) as signal intensity is directly proportional to voltage.

From Eq. (8), attenuation of the 151-MHz signal due to the flame is:

Attenuation due to the flame $(\mathrm{dB})=20 \log _{10}\left[\frac{0.899}{0.894}\right]$

$=0.048 \mathrm{~dB}$.
Observations reveal that soon after the flame had passed, signal amplitude remained lower than at D. The attenuation could be due to changes in the ground conductivity and scattering, which could have resulted from the removal of ground fuel. Attenuation-due changes in the vegetation cover and conductivity can be estimated to be:

Attenuation due hot flame $(\mathrm{dB})=20 \log _{10}\left[\frac{0.899}{0.897}\right]$

$$
=0.019 \mathrm{~dB} \text {. }
$$

\subsection{Attenuation of $30-\mathrm{MHz}$ signal}

The 30-MHz signal responded to path interception in the same way as the $151-\mathrm{MHz}$ signal. Unlike the Yagi antenna used in the $151-\mathrm{MHz}$ transmission, the quarterwavelength whip used for $30-\mathrm{MHz}$ signals spread energy in all directions. Consequently, reflections from fire crew and their equipment during $\mathbf{A}-\mathbf{C}$ affected the signal strength more significantly than at $151 \mathrm{MHz}$ (see Fig. 13). A prominent drop in the signal amplitude due to the fire was also observed between $\mathbf{D}$ and $\mathbf{E}$. It occurred at the same time as that of the $151-\mathrm{MHz}$ signal. The variation of the signal amplitude with time graphs is shown in Fig. 13.

On comparison of the responses of the 30 and $151-\mathrm{MHz}$ to grassfire interception, it was observed that the $151-\mathrm{MHz}$ signal remained below its average level before the fire, while the $30-\mathrm{MHz}$ signal quickly regained its strength 3 min after the fire.

Attenuation of a $30-\mathrm{MHz}$ signal due to the flame as calculated from Eq. (8) is:

Attenuation due to the flame $(\mathrm{dB})=20 \log _{10}\left[\frac{2.0111}{2.0050}\right]$

$$
=0.029 \mathrm{~dB} \text {. }
$$

Similarly, that due to the scattering is $0.0022 \mathrm{~dB}$.

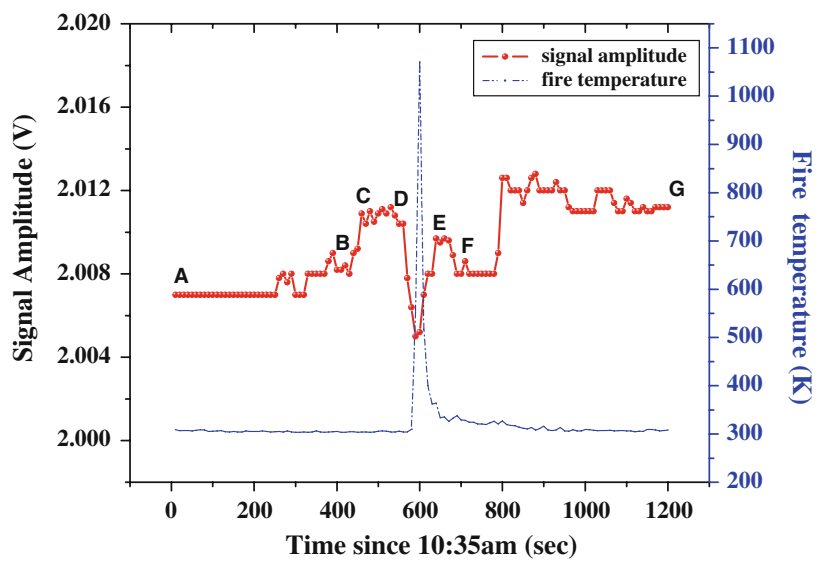

Fig. 13 30-MHz Smoothed signal amplitude versus time 


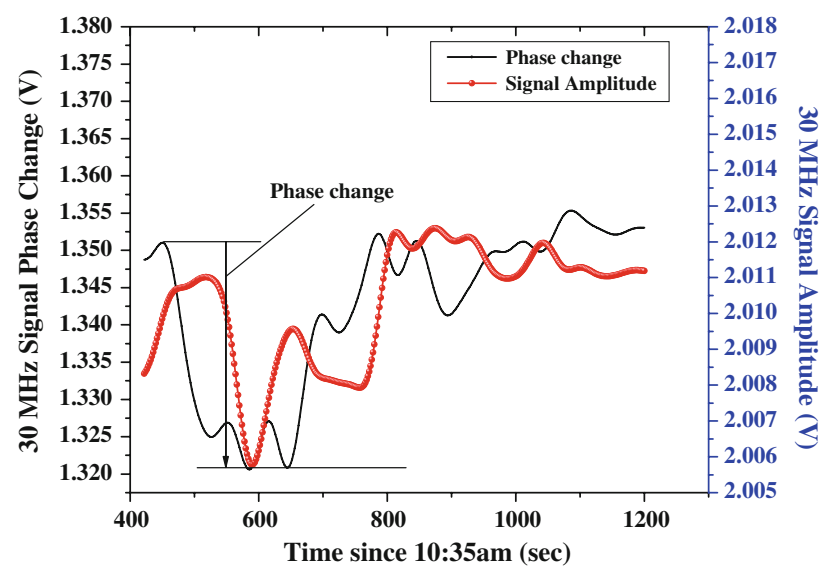

Fig. 14 Smoothed signal phase versus time graph

\subsection{0-MHz Signal phase change}

The phase on the $30-\mathrm{MHz}$ signal responded in much the same way to path interception by the grassfire front as the amplitude of both the $30-$ and $151-\mathrm{MHz}$ signals. A prominent drop in the signal phase due to the grassfire was observed to be at about 10.44:34 a.m. (Fig. 14). It occurred at nearly the same time as the drop between $\mathbf{D}$ and $\mathbf{E}$ for amplitude attenuation measurement at the two frequencies. The maximum drop for the $30-\mathrm{MHz}$ amplitude occurred at 10.44:45 a.m., while that of $151.3 \mathrm{MHz}$ occurred at 10.44:43 a.m.

The calculated phase shift induced on the $30-\mathrm{MHz}$ signal as worked out from Fig. 14 is $32.0 \mathrm{mV}$. From calibration measurement, it was observed that $10.4 \mathrm{mV}$ represents $1^{\circ}$ of phase change; therefore, $32 \mathrm{mV}$ is $3.08^{\circ}$.

\subsection{Other possible sources of attenuation and phase changes}

Signal attenuation could also be caused by depolarization of radio waves. The depolarization results from scattering of radio waves from vegetation. It increases with frequency for horizontally polarized signal and the reverse is true for vertically polarized waves. It ranges from 0.01 to 0.04 $\mathrm{dB} / \mathrm{m}$ in moist deciduous and wet evergreen dense tropical forests, respectively (Swarup and Tewari 1979). The experiment was performed in a sparsely vegetated savanna where depolarization is negligible. The influence of carbon soot in the combustion area is insignificant at radio wave frequencies, but at centimeter wavelengths (Kulemin and Razskazovsky 1997).

\subsection{Fuel characteristics and grassfire behavior}

The fuel characteristics have been calculated from Eqs. (16)-(19), while CSIRO Fire Spread Calculator was used to predict grassfire spread. The inputs to the calculator are: relative humidity; degree of curing; wind speed at $10 \mathrm{~m}$ and ambient temperature. Equations (16)-(19) were used to estimate the grassfire front depth. The intensity of the grassfire was calculated using the Byram's fire-line intensity equation (19).

From the ground data collected at the time of the experiment, it was noted that relative humidity was $37.8 \%$, wind at $1.5 \mathrm{~m}$ was $1.0 \mathrm{~m} / \mathrm{s}$ and ambient temperature was noted to be $28.9^{\circ} \mathrm{C}$. Since the fire spread calculator requires wind speeds measurements at $10 \mathrm{~m}$, the wind speed at $2 \mathrm{~m}$ can be used to estimate that at $10 \mathrm{~m}$ by the use of the relation (CSIRO Fire Spread Calculator 1998):

$U_{10} \approx 1.25 U_{2}$

From the wind speed at $1.5 \mathrm{~m}$, a correction for wind speed at $2 \mathrm{~m}$ can be done according to the relation given by Cheney et al. (1995) as:

$U_{2}=0.017+1.056 U_{1.5}$

Table 1 is a compilation of fuel characteristics and fire behavior as worked from the equations stated.

\subsection{Electron density calculation}

Propagation measurements show that the $151-\mathrm{MHz}$ signal is the most affected by scattering and changes in the ground conductivity than the $30-\mathrm{MHz}$ one. Attenuation of the 151$\mathrm{MHz}$ signal after the grassfire was nine (9) greater than imposed on the $30-\mathrm{MHz}$ one. Theoretically, attenuation due to the plasma effect imposed on the two frequencies should be of the same magnitude. When compared, the attenuation measurements may imply that a significant portion of $151-\mathrm{MHz}$ signal attenuation may be due to scattering. On the basis of this argument, $30-\mathrm{MHz}$ signal attenuation and phase change measurements are used to determine electron density in the grassfire plume. Applying Eqs. (12) and (13), the calculated electron density was $5.061 \times 10^{15} \mathrm{~m}^{-3}$.

Table 1 Fuel characteristic and fire behavior at plot B

\begin{tabular}{llllll}
\hline Fuel load $\left(\mathrm{tha}^{-1}\right)$ & Curing degree $(\%)$ & RoS $(\mathrm{m} / \mathrm{s})$ & Flame depth $(\mathrm{m})$ & Est'd. flame height $(\mathrm{m})$ & Intensity $\left(\mathrm{kg} / \mathrm{m}^{2}\right)(\mathrm{kW} / \mathrm{m})$ \\
\hline 0.462 & $90.1 \%$ & 0.06 & 0.89 & 2.5 & 554 \\
\hline
\end{tabular}




\section{Conclusions}

The prescribed grassfire in the experiment was of moderate intensity; thus, Byram's grassfire intensity was observed to be $554 \mathrm{~kW} \mathrm{~m}^{-1}$. Maximum temperature measured was $1071 \mathrm{~K}$ at $0.75 \mathrm{~m}$ above the ground inside the grass fuel stratum. The rate of spread for this fire was approximately $0.06 \mathrm{~m} \mathrm{~s}^{-1}$. The flame was slightly tilted in the direction of the wind. The grass was $90.1 \%$ dry. The depth of the flame was around $0.89 \mathrm{~m}$

At $151 \mathrm{MHz}$, maximum attenuation coefficient of the signal intensity due to the grassfire flame was observed to be $0.054 \mathrm{~dB} \mathrm{~m}^{-1}$. Scattering from hot ground surface after the fire induced a $0.021 \mathrm{~dB} \mathrm{~m}^{-1}$ signal loss. The loss was slightly lower for a $30-\mathrm{MHz}$ signal with a maximum attenuation of $0.033 \mathrm{~dB} \mathrm{~m}^{-1}$ when it was intercepted by the flame. The hot ground surface also slightly affected the $30-\mathrm{MHz}$ signal as it attenuated the signal by $0.003 \mathrm{~dB} \mathrm{~m}^{-1}$.

The phase shift induced on the $30-\mathrm{MHz}$ signal was significant. A maximum phase shift of $3.08^{\circ}$ was observed as the signal path was intercepted by the grassfire. With this amount of phase shift and the geometry of the experiment, it was estimated from Eq. (12) that the maximum electron density in the grassfire was $5.061 \times 10^{15} \mathrm{~m}^{-3}$ when effective collision frequency of $1.2 \times 10^{11} \mathrm{~s}^{-1}$ was used.

Acknowledgments We would like to gratefully acknowledge the Staff Development Office of the University of Botswana for the financial support for this work. The work was partly supported by Emergency Management Australia under project no. 60/2001.

\section{References}

Akhtar K, Scharer EJ, Tysk SM, Kho E (2003) Plasma interferometry at high pressures. Rev Sci Instrum 74(2):996-1001

Alkamade CTh, Hollander TJ, Snelleman W, Zeegers PJTh (1982) Metal vapours in flames. Pergamon Press, New York, 460 pp

Boan J (2006) Radio communication in fire environments. In: Proceedings of the Wars 2006 Conference, Leura, NSW, Australia

Boan J (2007) Radio Experiments with fire. IEEE Antennas Wireless Propag Lett 6:411-414

Brohez S, Delvosalle C, Marlair G (2004) A two thermocouples probe for radiation correction of measured temperatures in compartment fires. Fire Safety J 39(5):399-411

Butler CJ, Hayhurst AN (1998) Kinetics of gas-phase ionization of an alkali metal, A, by the electron and proton transfer reactions: $\mathrm{A}+\mathrm{H}_{3} \mathrm{O}^{+} \rightarrow \mathrm{A}+. \mathrm{H}_{2} \mathrm{O}+\mathrm{H} ; \quad \mathrm{AOH}+\mathrm{AOH} 2^{+}+\mathrm{H}_{2} \mathrm{O}$ in fuel-rich flames at 1800-2250 K. J Chem Soc Faraday Trans 98:2729-2734

Caron PR (1968) Techniques of measuring the electron density of dense, thick, steady state plasmas. IEEE Antenna Propag Mag $1: 611-612$

Cheney NP, Gould JS (1995) Fire growth to quasi-steady state rate for forward spread. Int J Wildl Fire 5(4):237-247
Cruz MG, Fernandes PM (2008) Development of fuel models for fire behavior prediction in maritime pine (Pinus pinister Ait) stands. Int J Wildland Fire 17(2):194-204

Dupuy JL, Marechal J, Morvan D (2003) Fires from a cylindrical forest fuel burner: combustion dynamics and flame properties. Combust Flame 135:65-76

Foster T (1976) Bushfire: history, prevention and control. A. H. and A.W. Reed Pty Ltd, Sydney, 26 pp

Gilchrist BE, Ohler SG, Gallimore AD (1997) Flexible microwave system to measure the electron number density and quantify the communications impact of electric thruster plasma plumes. Rev Sci Instrum 68(2):1189-1194

Griffiths B, Booth D (2001) The effects of fire and smoke on vhf radio communications. Country Fire Association, Investigative Report COMM-REP-038-1

Guo B, Wang X (2005) Power absorption of high frequency electromagnetic waves in a partially ionized plasma layer in atmospheric conditions. Plasma Sci Technol 7:2645-2648

Hata M, Shigeyuki D (1983) Propagation tests for $23 \mathrm{GHz}$ and 40 GHz. IEEE J Selected Areas Commun 1(4):658-673

Haught AF (1962) Shock tube investigation of caesium vapour. Phys Fluids 5(11):1337-1346

Hofmann FW (1966) Control of plasma collision frequency for alleviation of signal degradation. IEEE Trans Commun Technol 3:318-323

Howlader MK, Yang Y, Roth RJ (2005) Time-resolved measurements of electron number density and collision frequencies for fluorescent lamp plasma using microwave diagnostics. IEEE Trans Plasma Sci 33:1093-1099

Jamison SP, Shen J, Jones DR, Isaac RC, Ersfeld B, Clark D, Jaroszynski DA (2003) Plasma characterization with Terahertz time-domain measurements. J Appl Phys 93:4334-4336

Knudsen JN, Jensen PA, Dam-Johansen K (2004) Transformation and release to the gas phase of $\mathrm{Cl}, \mathrm{K}$, and $\mathrm{S}$ during combustion of annual biomass. Energy Fuels 18:1385-1399

Koretzsky E, Kuo SP (1998) Characterization of atmospheric pressure plasma generated by a plasma torch array. Phys Plasmas 5:37743780

Kulemin GP, Razskazovsky VB (1997) Radar reflection from explosion and gas wake of operating engines. IEEE Trans Antenna Propag 45:731-739

Laroussi M, Roth JR (1993) Numerical calculation of the reflection, absorption and transmission of microwaves by a non-uniform plasma slab. IEEE Trans Plasma Sci 21:366-372

Latham D (1999) Space charge generated by wind tunnel fires. Atmospheric Res 51:267-278

Lokker C (2000) Draft revegetation strategy for the Townsville City Council. Townsville City Council, Townsville

Mphale KM (2008) Radio wave propagation and prediction in wildfires. PhD thesis, James Cook University, Townsville, QLD

Mphale K, Heron ML (2007) Plant alkali content and radio wave communication efficiency in high intensity savanna wildfires. J Atmospheric Solar-Terrestrial Phys 69:471-484

Nesterko NA, Taran EN (1971) Ionization and radiation of alkali metals in acetylene-air flame plasma, with halogen additions. J Appl Spectrosc 14(2):242-244

Preston CM, Schmidt MWI (2006) Black (Pyrogenic) carbon in boreal forests: a synthesis of current knowledge and uncertainties. Biogeosci Discuss 3:211-271

Raison RJ, Khaina PK, Woods P (1985) Mechanisms of element transfer to the atmosphere during vegetation burning. Can J For Res 15:132-140

Santoru J, Gregorie DJ (1993) Electromagnetic wave absorption in highly collisional plasma. J Appl Phys 74(6):3736-3743

Schneider J, Hofmann FW (1959) Absorption and dispersion of microwave in flames. Phys Rev 6:244-249 
Semenov ES, Sokolik AS (1970) Thermal and chemical ionization in flames combustion. Explosion Shock Waves 6(1):33-43

Shannon KS, Butler BW (2003) A review of error associated with thermocouple temperature measurement in fire environments. Second international wildland fire ecology an fire management congress and fifth symposium on fire and forest meteorology. American Meteorological Society, Orlando, FL, 16-20 November 2003, 7B.4, p 3

Shuler KE, Weber J (1954) A microwave investigation of the ionization of hydrogen-oxygen and acetylene-oxygen flames. J Chem Phys 22:491-502

Sicha M (1979) Measurement of the electron energy distribution function in a flame plasma at atmospheric pressure. Czechoslovak J Phys 29:640-645

Silvani X, Morandini F (2009) Fire spread experiments in the field: temperature and heat fluxes measurements. Fire Safety J 44:279285

Sodha MS, Palumbo CJ, Daley JT (1963) Effect of solid particle on electromagnetic properties of rocket exhaust. Br J Appl Phys 14:916-919
Sullivan AL (1997) Convective Froude and Byram's energy criterion for Australian experimental grassland fires. Proc Comb Inst 31:2557-2564

Swarup S, Tewari RK (1979) Depolarization of radio waves in jungle environment. IEEE Trans Antennas Prop 27(1):113-116

Uhm HS (1999) Properties of plasmas generated by electrical breakdown in flames. Phys Plasmas 6(11):4366-4374

Vodacek A, Kremens RL, Fordham SC, VanGorden SC, Luisi D, Schott JR, Latham DJ (2002) Remote optical detection of biomass burning using potassium emission signature. Int $\mathbf{J}$ Remote Sens 23(13):2721-2726

Williams DW, Adams JS, Batten JJ, Whitty GF, Richardson GT (1970) Operation Euroka: An Australian Mass Fire Experiment. Report 386, Maribyrnor, Victoria, Australia, Defense Standards Laboratory

Williams RP, Congdon RA, Grice AC, Clarke PJ (2003) Effect of fire regime on plant abundance in tropical eucalypt savanna of northeastern Australia. Austral Ecol 28:327-338

Zivanovic SV, Musal HM, Primich IR (1964) Determination of plasma layer properties form the measured electromagnetic transmission coefficient. IEEE Trans Antennas Propag 1:618-624 